Original Article

\title{
Production of Ethyl Biodiesel from Catfish Oil by New Method Using Ethyl Biodiesel as Co-Solvent
}

\author{
Nguyen Thị Son*, Hoang Luong Nghia, Pham Van Quang, Luu Van Boi \\ VNU University of Science, 334 Nguyen Trai, Hanoi, Vietnam \\ Received 07 October 2020 \\ Revised 04 November 2020; Accepted 04 November 2020
}

\begin{abstract}
In this study, ethyl biodiesel (FAEE) from catfish oil was produced by a new method using FAEE as co-solvent. The study results show that due to the short reaction time with very high conversion (> 99\%) and there was no need to remove the FAEE co-solvent, the cost of the product was reduced by about $30 \%$. FAEE, a multipurpose product, can be used as an engine fuel itself and its ester-rich fraction of omega-3, $-6,-9$ acids can also be extracted to produce high added value supplements.
\end{abstract}

Keywords: Catfish oil, Ethanol, Ethyl carboxylate, ethyl biodiesel, Omega-3,-6,-9 acid esters, cosolvent, co-solvent method.

\footnotetext{
* Corresponding author.

Email address: sonhuco@yahoo.com 


\title{
Nghiên cứu chế tạo etyl biodiesel từ mỡ cá tra bằng phương pháp mới, sử dụng đồng dung môi etyl biodiesel
}

\author{
Nguyễn Thị Sơn*, Hoàng Lường Nghĩa, Phạm Văn Quang, Lưu Văn Bôi \\ Truờng Đại học Khoa học Tự nhiên, ĐHQGHN, 334 Nguyễn Trãa, Hà Nội, Việt Nam \\ Nhận ngày 07 tháng 10 năm 2020 \\ Chỉnh sửa ngày 04 tháng 11 năm 2020; Chấp nhận đăng ngày 04 tháng 11 năm 2020
}

\begin{abstract}
Tóm tắt: Hàng năm, từ phế thải của quá trình chế biến cá tra ở đồng bằng sông Mekong (ĐBSMK) chiết xuất ra khoảng 150.000 tấn dầu cá, trong đó $50 \%$ được tinh luyện thành dầu ăn, phần còn lại dùng làm nguyên liệu sản xuất thức ăn chăn nuôi hoặc dầu diesel sinh học. Thức ăn chăn nuôi giá rất rẻ, hiệu quả kinh tế thấp. Dầu diesel sinh học đang được sản xuất theo phương pháp truyền thống, tiêu tốn nhiều thời gian và năng lượng, dẫn đến giá thành cao. Hơn nữa, nếu chỉ sản xuất một sản phẩm từ dầu cá thì trong tình hình giá dầu đang giảm mạnh như hiện nay, biodiesel không thể cạnh tranh được với diesel dầu mỏ. Trong nghiên cứu này, dầu diesel sinh học chứa gốc etyl (FAEE) từ mỡ cá tra được sản xuất theo phương pháp mới, sử dụng FAEE làm đồng dung môi. Kết quả cho thấy do thời gian phản ứng ngắn với độ chuyển hóa rất cao (> 99\%) và không cần cất loại đồng dung môi FAEE nên giá thành sản phẩm giảm khoảng $30 \%$. FAEE là sản phẩm đa ứng dụng, có thể dùng làm nhiên liệu động cơ và phân đoạn giàu este của các axit omega-3, -6, -9 có thể được tách ra để sản xuất thực phẩm chức năng có giá trị gia tăng cao.
\end{abstract}

Tù khóa: Mỡ cá tra, Etanol, Etyl cacboxylate, Etyl biodiesel, Este axit omega-3,-6,-9, Đồng dung môi, Phương pháp đồng dung môi.

\section{Mở đầu}

\subsection{Phương pháp}

Mỗi năm, các doanh nghiệp và nông dân ĐBSMK sản xuất được khoảng 1,5 triệu tấn cá tra. Quá trình chế biến cá phát sinh khoảng 800.000 tấn phụ phẩm, gồm đầu, da, xương, mỡ,... Từ số phụ phẩm này đã trích ly được khoảng 150.000 tấn dầu cá. Khoảng $50 \%$ số mỡ cá này được tinh luyện làm dầu ăn, số còn lại được sử dụng làm nguyên liệu sản xuất thức ăn gia súc hoặc biodiesel [1]. Thức ăn gia súc có giá thành rẻ, hiệu quả kinh tế thấp. Sản xuất biodiesel để thay thế một phần nhiên liệu hóa thạch, góp phần giảm thiểu ô nhiễm môi trường là hướng phát triển tốt. Tuy nhiên, hiện tại biodiesel đang đối mặt với hai thử thách. Một là, sản xuất bằng công nghệ truyền thống [2,3] tốn nhiều thời gian và năng lượng dẫn đến chi phí cao. Hai là, trong tình hình giá dầu mỏ giảm sâu, nếu chỉ sản xuất 1 loại sản phẩm, thì biodiesel rất khó cạnh tranh. Trong khi đó dầu cá tra là loại nguyên liệu quý, thu hút sự quan tâm nghiên cứu của nhiều nhà khoa học, nhằm sản xuất các sản phẩm có giá trị gia tăng cao [4]. Theo kết quả phân tích của các tác giả [5] trong dầu cá tra, ngoài các axit béo no, chủ yếu là axit palmitic và stearic chiếm khoảng $39 \%$; còn có nhiều axit béo không no một nối đôi (omega-9) 37\%; axit không no 2 nối đôi (omega-6) 19\% và các axit chứa 3 nối đôi (omega-3) trở lên 4-5\%.

Trong công trình này đã nghiên cứu chế tạo este etyl cacboxylat (còn gọi là etyl biodiesel

\footnotetext{
* Tác giả liên hệ.

Địa chi email: sonhuco@yahoo.com

https://doi.org/10.25073/2588-1140/vnunst.5137
} 
hoặc FAEE) từ mỡ cá tra và rượu etanol bằng phương pháp mới, sử dụng chính sản phẩm phản ứng là FAEE làm đồng dung môi, nhằm 2 mục tiêu. Một là, nâng cao hiệu suất etyl biodiesel. Hai là, xác định hàm lượng các este của các axit béo không no, để đánh giá khả năng tách các axit omega-3,-6,-9 làm thực phẩm chức năng trong tương lai.

\section{Thực nghiệm}

\subsection{Hóa chất:}

- Etyl oleate; Etyl linoleate; Etyl linolenate; Etyl cis-5,8,11,14,17-Eicosapentaenoate và Etyl cis-4,7,10,13,16,19-Docosahexaenoate

- Chất nội chuẩn n-hexadecane ( IS) của hãng Sigma.

- Axeton, metanol, etanol, diclometan, axetonitril: hóa chất tinh khiết của hãng Merck; Mỡ cá tra được mua từ An Giang.

- Metanol, etanol, axeton, axetonitril kỹ thuật, khan $(99,5 \%)$ của Hàn Quốc, và Malaysia

\subsection{Thiết bị:}

- Máy đo hàm lượng nước Karl-Fishe MKC501 của hãng KEM, Nhật Bản.

- Dung dịch chuẩn độ $\mathrm{NaOH} 0,01 \mathrm{~N}$, Việt Nam, được kiểm tra lại trước khi dùng bằng chuẩn độ với dung dịch chuẩn axit oxalic. Phenolphtalein: Chất chuẩn của Sigma.

- Cân phân tích độ chính xác 0,0001 (Presica, Thụy Sỹ), cân kỹ thuật độ chính xác $0,01 \mathrm{~g}$ (Presica, Thụy Sỹ).

a) Xác định hàm lượng nước:

Hàm lượng nước trong mỡ cá được xác định trên máy Karl Fisher, dựa trên sự mất màu của iod trong phản ứng với $\mathrm{SO}_{2}$ theo phản ứng:

$$
\mathrm{I}_{2}+\mathrm{SO}_{2}+2 \mathrm{H}_{2} \mathrm{O} \leftrightarrow 2 \mathrm{HI}+\mathrm{H}_{2} \mathrm{SO}_{4}
$$

Cách tiến hành: Bật công tắc khởi động máy Karl Fisher và chờ đển khi máy hoạt động ổn định. Dùng micropipet hút $20 \mu 1$ mẫu, cân và ghi lại khối lượng $\mathrm{m}_{1}$. Bơm mẫu vào máy, cân và ghi lại khối lượng micropipet $\mathrm{m}_{2}$. Sau khi phản ứng kết thúc, nhập khối lượng $\mathrm{m}_{1}$ và $\mathrm{m}_{2}$ vào máy, kết quả hàm lượng nước được hiển thị trên màn hình.

Kết quả cho thấy, hàm lượng nước trong mẫu là 241ppm, tốt hơn giới hạn cho phép để tổng hợp etyl cacboxylat (etyl biodiesel) theo phương pháp chuyển đổi este.

b) Xác định hàm lượng axit béo tự do:

Hàm lượng axit béo tự do (FFA) của mỡ cá được xác định bằng phương pháp chuẩn độ axitbazo.

Cách tiến hành: cân $1 \mathrm{~g}$ mõ cá cho vào bình nón $250 \mathrm{ml}$. Hòa tan mẫu bằng $50 \mathrm{ml}$ axeton khan đã được đun nóng và chuẩn độ bằng dung dịch $\mathrm{NaOH} 0,01 \mathrm{~N}$ với chỉ thị phenolphtalein đến khi dung dịch chuyển từ không màu sang màu hồng nhạt bền trong 30 giây

Hàm lượng FFA được tính theo công thức:

$$
\operatorname{FFA}(\%)=\frac{C(\mathrm{NaOH}) \cdot \mathrm{V}(\mathrm{NaOH}) \cdot \mathrm{M}(\mathrm{FFA}) \cdot 100}{1000}
$$

Trong đó: $\mathrm{M}(F F A)$ là trung bình cộng khối lượng phân tử của các axit béo tự do có trong dầu mỡ động thực vật, với dầu cá tra thì $\mathrm{M}=285$. $\mathrm{V}$ $(\mathrm{NaOH})$ là thể tích dung dịch $\mathrm{NaOH}$ tiêu tốn để chuẩn độ. $\mathrm{C}(\mathrm{NaOH})$ là nồng độ dung dịch $\mathrm{NaOH}$ $(0,01 \mathrm{~N})$.

Kết quả tính toán hàm lượng axit béo tự do trong mỡ cá tra được thể hiện ở Bảng 1 .

Bảng 1. Kết quả xác định hàm lượng FFA trong mõ cá tra

\begin{tabular}{|c|c|c|c|}
\hline TT & $\begin{array}{c}\text { Khối lượng } \\
\text { mâ̂u (gam) }\end{array}$ & $\begin{array}{c}\text { Thể tích } \mathrm{NaOH} \\
(\mathrm{ml})\end{array}$ & $\begin{array}{c}\text { Hàm lượng } \\
\text { FFA }(\%)\end{array}$ \\
\hline 1 & 1,0138 & 9,53 & 2,68 \\
\hline 2 & 1,0015 & 9,35 & 2,66 \\
\hline 3 & 0,9991 & 9,36 & 2,67 \\
\hline
\end{tabular}

Từ kết quả trên cho thấy, mỡ cá tra chứa $2,67 \%$ FFA, đạt yêu cầu để tổng hợp este cacboxylat (etyl biodiesel) bằng phương pháp một giai đoạn - chuyển đổi este với xúc tác $\mathrm{KOH}$.

2.4. Chế tạo etyl biodiesel tù mõ cá tra bằng phưong pháp đồng dung môi

a) Quy trình chung chế tạo FAEE từ mỡ cá tra:

Cho hỗn hợp 50g mỡ cá đã được hòa tan trong đồng dung môi $\mathrm{FAEE}$ vào bình cầu 3 cổ 
$250 \mathrm{ml}$ có lắp sinh hàn hồi lưu. Sau đó cho tiếp vào bình phản ứng lượng xúc tác $\mathrm{KOH}$ đã hòa tan trong etanol. Khuấy và đun hồi lưu cách thủy hỗn hợp phản ứng trong thời gian nhất định trên bếp khuấy từ. Trong thời gian phản ứng, 5 phút 1 lần, dùng xilanh có kim tiêm lấy mẫu qua nút teflon cho vào ống nghiệm đựng dung dịch axit photphoric $2 \%$. Lắc đều, hút lớp dầu ở trên, làm khô bằng natri sunphat khan. Kiểm tra độ chuyển hóa este trên máy UFLC với chất nội chuẩn là $n$ hexadecane. Khi kết thúc phản ứng, cất loại etanol dư. Để nguội, rót hỗn hợp phản ứng vào phễu chiết, tách lớp glycerin ở dưới; rửa phần biodiesel thô còn lại 3 lần bằng dung dịch axit photphoric $2 \%$ hâm nóng $40-50^{\circ} \mathrm{C}$, mồi lần 50 ml. Rửa lại 2 lần bằng nước sạch. Làm khô FAEE bằng natri sunphat khan, lọc lấy sản phẩm. Hiệu suất đạt $82 \%$.

Chất lượng (hàm lượng nước và $\mathrm{FFA}$ được kiểm tra bằng các phương pháp mô tả trong mục 2.3a,b. Độ chuyển hóa etyl biodiesel được kiểm tra trên máy UFLC (xem Hình 1 phần kết quả và thảo luận).

b) Khảo sát các yếu tố ảnh hưởng lên hiệu suất của FAEE:

Phản ứng chuyển đổi este được thực hiện như quy trình chung (a). Những yếu tố được khảo sát gồm: Tỷ lệ mol của mỡ/etanol; hàm lượng \% của xúc tác $\mathrm{KOH}$ (so với khối lượng (KL) mỡ cá); hàm lượng \% đồng dung môi FAEE (so với KL mỡ cá); nhiệt độ và thời gian phản ứng. Kết quả khảo sát được đưa ra trong Bảng 2 (xem phần kết quả và thảo luận).

\subsection{Xác định điểm sương và điểm đông đặc của FAEE}

Điểm sương $(\mathrm{CP})$ và điểm đông đặc $(\mathrm{PP})$ của etyl biodiesel được xác định theo phương pháp tiêu chuẩn ASTM D97: Mẫu $30 \mathrm{~g}$ FAEE được cho vào bình nón, lắc đều và đun nóng đến $40^{\circ} \mathrm{C}$, để nguội đến $30^{\circ} \mathrm{C}$, rót vào ống nghiệm đặc chủng. Điểm sương và điểm đông đặc của $\mathrm{FAEE}$ được xác định trên máy KLA-3 của hãng Kohler, Hoa kỳ.

Kết quả đo điểm sương của $\mathrm{FAEE}$ là $24^{\circ} \mathrm{C}$ và điểm đông đặc là $14^{\circ} \mathrm{C}$.
2.6. Xác định hàm lựng các axit béo không no chủ yếu trong mõ cá

Các este không no trong mỡ cá cần xác định: Etyl oleate (omega-9); Etyl linoleate (omega-6); Etyl linolenate (Omega-3); Etyl cis5,8,11,14,17-Eicosapentaenoate (EPA) và Etyl cis-4,7,10,13,16,19-Docosahexaenoate (DHA).

2.6.1. Xây dựng đường chuẩn các mẫu FAEE cần xác định

Đường chuẩn được xây dựng trên cơ sở các chất chuẩn Etyl oleate; Etyl linoleate; Etyl linolenate; Etyl cis-5,8,11,14,17-Eicosapentaenoate và Etyl cis-4,7,10,13,16,19-Docosahexaenoate

a) Điều kiện chạy sắc ký GC:

- Dung môi: $\mathrm{CH}_{2} \mathrm{Cl}_{2}$;

- Buồng bơm: Nhiệt độ đầu bơm $260^{\circ} \mathrm{C}$;

- Tỉ lệ chia dòng: 10:1;

- Khí mang: Ni-tơ $\left(\mathrm{N}_{2}\right)$, tốc độ dòng khí $20 \mathrm{~cm}^{3} /$ giây;

- Thể tích bơm mẫu: $1 \mu \mathrm{l}$;

- Mẫu: hỗn hợp 37 FAME trong dung môi $\mathrm{CH}_{2} \mathrm{Cl}_{2}$;

- Cột: cột mao quản SP-2560 (100m $\times 0,25 \mathrm{~mm} \times 0,25 \mu \mathrm{m})$;

- Lò: Nhiệt độ ban đầu là $60^{\circ} \mathrm{C}$, giữ 3 phút, tăng $15^{\circ} \mathrm{C}$ phút lên $150^{\circ} \mathrm{C}$, giữ 1 phút, tăng $2,5^{\circ} \mathrm{C} /$ phút lên $200^{\circ} \mathrm{C}$, giữ 2 phút, tăng $5^{\circ} \mathrm{C} /$ phút lên $240^{\circ} \mathrm{C}$, giữ 15 phút. Tổng là 55 phút.

- Detector: FID, nhiệt độ $260^{\circ} \mathrm{C}$, tốc độ khí $\mathrm{H}_{2}: 40 \mathrm{~mL} /$ phút, tốc độ không khí là $400 \mathrm{~mL} /$ phút.

b) Nồng độ các chất chuẩn FAEE dùng để xây dựng đường chuẩn

- Nồng độ 200-400-600ppm

- Nồng độ 100-200-300ppm

- Nồng độ 40-80-120ppm

- Nồng độ 10-20-30ppm

2.6.2. Xác định hàm lượng 5 FAEE không no chủ yếu trong mỡ cá:

Cân một lượng $250 \mathrm{mg}$ cho vào bình định mức $10 \mathrm{ml}$, thêm dung môi diclometan cho tới vạch. Lấy $20 \mu \mathrm{l}$ bơm vào cột $\mathrm{GC}$. 
Đối với các FAEE có hàm lượng lớn thì pha loãng dung dịch ban đầu 10 lần rồi tiến hành chạy sắc kí.

Sau khi thu được sắc kí đồ, dựa vào thời gian lưu để định danh FAEE cụ thể. Căn cứ đường chuẩn nồng độ, hàm lượng các FAEE trong dung dịch $(\mathrm{Ci})$ được tính toán bằng công thức:

$\%$ FAEEi $=\frac{C i \times 10 \times F p l \times 100}{M}$

Trong đó:

- \% FAEEi là hàm lượng tính theo phần trăm của etyl este thứ i. mẫu.

- Ci là nồng độ của este thứ i trong dung dịch

- Fpl là 10 đối với các $\mathrm{FAEE}$ có hàm lượng lớn $(\mathrm{C} 18: 1 ; \mathrm{C} 18: 2)$ với các $\mathrm{FAEE}$ còn lại thì $\mathrm{Fpl}=1$.

- M là khối lượng biodiesel dùng pha mẫu.

Kết quả xác định hàm lượng 5 FAEE chế tạo từ mỡ cá tra được đưa ra trong Bảng 3 (xem phần kết quả và thảo luận).

\section{Kết quả và thảo luận}

\subsection{Nghiên cứu chế tạo etyl biodiesel (FAEE)}

Biodiesel (BDF) là hỗn hợp các este của các axit béo được tạo thành từ phản ứng chuyển đổi este giữa triglycerid (TG) trong dầu mỡ động thực vật với các rượu khối lượng phân tử thấp. Cho đến nay, metanol là rượu được dùng nhiều nhất để sản xuất biodiesel. Một mặt, do giá thành metanol tương đối thấp. Mặt khác, do metanol có một số ưu điểm về kỹ thuật, như mạch cabon ngắn, độ phân cực lớn, nên khả năng phản ứng cao; tạo nhũ tương với glycerin và biodiesel không bền, nên dễ tách và làm sạch [7]. Tuy nhiên, metanol có những nhược điểm quan trọng. Trước hết là độc tính cao; tiếp theo, gọi metyl biodiesel là nhiên liệu tái tạo đang gây tranh cãi, vì hiện nay metanol được sản xuất chủ yếu từ khí dầu mỏ.

Trong khi đó etanol được sản xuất từ các nguyên liệu nguồn gốc thực vật, do đó etyl biodiesel đúng nghĩa là nhiên liệu tái tạo. So với metanol, etanol ít độc hơn, nhiệt năng cao hơn, nhiệt độ kết tinh thấp hơn, tính chất lưu biến tốt hơn; tính ổn định oxy hóa, tính bôi trơn, khả năng phân hủy sinh học và đặc tính khí thải đều tốt hơn [8-11]. Tuy nhiên, sản xuất biodiesel từ etanol với xúc tác $\mathrm{KOH}$ có 2 nhược điểm đáng chú ý. Thứ nhất, mạch cacbon dài hơn metanol, nên khả năng phản ứng kém hơn. Thứ hai, so với metanol, etanol tạo nhũ tương bền hơn với glycerin và biodiesel, nên việc tách và làm sạch sản phẩm khó khăn hơn $[9,10]$. Gần đây, vì tầm quan trọng của sự phát triển bền vững nhiên liệu tái tạo, rất nhiều nhà khoa học thuộc lĩnh vực đã rất quan tâm đến etyl biodiesel. Rất nhiều giải pháp công nghệ đã được đề xuất nhằm cải thiện quá trình tách etyl biodiesel sau phản ứng [1216]. Do đó, nghiên cứu phương pháp mới chế tạo etyl biodiesel sử dụng FAEE làm đồng dung môi của các tác giả công trình này, nhằm nâng cao hiệu suất, hướng đến đa dạng hóa sản phẩm từ etyl biodiesel có ý nghĩa khoa học và thực tiễn cần thiết.

Như đã biết, hiện nay, biodiesel được sản xuất chủ yếu theo phương pháp truyền thống, trên cơ sở phản ứng giữa triglycerid trong dầu mõ̃ động thực vật với các ancol phân tử lượng thấp, có mặt xúc tác. Vì dầu mỡ nguyên liệu ít tan trong ancol, nên phản ứng chỉ xảy ra trên bề mặt pha, do đó phải đun khuấy mạnh; thời gian phản ứng dài; tiêu tốn nhiều năng lượng; độ chuyển hóa thấp; chất thải nhiều, tách sản phẩm khó khăn, dẫn đến giá thành sản phẩm cao. Phương pháp đồng dung môi là sử dụng một chất lỏng hữu cơ, trong nghiên cứu này là $\mathrm{FAEE}$ (sản phẩm etyl biodiesel của phản ứng) có khả năng hòa tan tốt cả mỡ cá và etanol, làm cho phản ứng được xảy ra trong môi trường đồng thể, tốc độ phản ứng cao, thời gian phản ứng ngắn, độ chuyển hóa rất cao, chất thải ít, tách sản phẩm nhanh. Để tìm được điều kiện thích hợp cho phản ứng chuyển đổi este của mỡ cá tra bằng etanol với xúc tác $\mathrm{KOH}$, đã tiến hành nghiên cứu ảnh hưởng của tỷ lệ mol mỡ/etanol, hàm lượng xúc tác (\% khối lượng mỡ cá), hàm lượng đồng dung môi FAEE (\% khối lượng mỡ cá), thời gian và nhiệt độ, lên hiệu suất etyl biodiesel.

Quá trình khảo sát được thực hiện như mục $2.4 \mathrm{a}$ và $2.4 \mathrm{~b}$ của phần thực nghiệm. Kết quả được đưa ra trong Bảng 2. 
Bảng 2. Ảnh hưởng của tỷ lệ mol mỡ/EtOH, \% $\mathrm{KOH}, \%$ đồng dung môi FAEE, nhiệt độ và thời gian phản ứng lên hiệu suất $\mathrm{FAEE}$

\begin{tabular}{|c|c|c|c|c|c|c|}
\hline TT & $\begin{array}{c}\text { Mỡ cá/ } \\
\text { EtOH, } \\
\text { mol/ } \\
\text { mol }\end{array}$ & $\begin{array}{c}\text { KOH, KL } \\
\text { \% Ká } \\
\text { mó cá }\end{array}$ & $\begin{array}{c}\text { Dung } \\
\text { môi } \\
\text { FAEE, } \\
\text { KL } \\
\text { mơ cá }\end{array}$ & $\begin{array}{c}\text { Thời } \\
\text { gian, } \\
\text { phút }\end{array}$ & $\begin{array}{c}\text { Nhiệt } \\
\text { độ, } \\
{ }^{\circ} \text { C }\end{array}$ & $\begin{array}{c}\eta \\
\text { FAEE, } \\
\%\end{array}$ \\
\hline 1 & $1 / 3$ & 1,2 & 25 & 90 & 70 & 56 \\
\hline 2 & $1 / 4$ & 1,2 & 25 & 90 & 70 & 60 \\
\hline 3 & $1 / 6$ & 1.2 & 25 & 90 & 70 & 64 \\
\hline 4 & $1 / 8$ & 1.2 & 25 & 90 & 70 & 82 \\
\hline 5 & $1 / 10$ & 1.2 & 25 & 90 & 70 & 83 \\
\hline 6 & $1 / 8$ & 0.5 & 25 & 90 & 70 & 45 \\
\hline 7 & $1 / 8$ & 1.0 & 25 & 90 & 70 & 70 \\
\hline 8 & $1 / 8$ & 1.2 & 25 & 90 & 70 & 82 \\
\hline 9 & $1 / 8$ & 1.5 & 25 & 90 & 70 & 80 \\
\hline 10 & $1 / 8$ & 1.2 & 10 & 90 & 70 & 60 \\
\hline 11 & $1 / 8$ & 1.2 & 15 & 90 & 70 & 70 \\
\hline 12 & $1 / 8$ & 1.2 & 20 & 90 & 70 & 83 \\
\hline 13 & $1 / 8$ & 1.2 & 30 & 90 & 70 & 80 \\
\hline 14 & $1 / 8$ & 1.2 & 20 & 80 & 70 & 81 \\
\hline 15 & $1 / 8$ & 1.2 & 20 & 70 & 70 & 80 \\
\hline 16 & $1 / 8$ & 1.2 & 20 & 60 & 70 & 78 \\
\hline 17 & $1 / 8$ & 1.2 & 20 & 90 & 78 & 82 \\
\hline 18 & $1 / 8$ & 1.2 & 20 & 90 & 60 & 72 \\
\hline 19 & $1 / 8$ & 1.2 & 20 & 90 & 50 & 64 \\
\hline
\end{tabular}

Dựa vào kết quả thu được trên Bảng 2 , có thể thấy điều kiện thích hợp nhất để phản ứng giữa mỡ cá tra với etanol có mặt xúc tác $\mathrm{KOH}$ là: tỷ lệ mol mỡ cá/etanol -1/8; hàm lượng $\mathrm{KOH}$ $1,2 \%$ (KL mỡ cá); hàm lượng đồng dung môi FAEE - 20\% (KL mỡ cá); nhiệt độ - $70^{\circ} \mathrm{C}$ và thời gian - 90 phút. Ở những điều kiện ấy, hiệu suất FAEE đạt $83 \%$ (sau khi trừ lượng FAEE đồng dung môi).

Chất lượng sản phẩm etyl biodiesel của phản ứng đã được kiểm tra bằng các phương pháp mô tả trong phần thực nghiệm. Độ chuyển hóa este được xác định bằng sắc ký lỏng siêu nhanh (UFLC) với chất nội chuẩn là n-hexadecane. Kết quả thể hiện trên sắc ký đồ Hình $\mathbf{1 b}$. Để so sánh, đã ghi sắc ký đồ của dầu cá nguyên liệu, thể hiện trên Hình 1a. Trên sắc ký đồ $\mathbf{1 a}$, pic nội chuẩn xuất hiện với thời gian lưu ở 16,796 phút. Phía trái pic nội chuẩn là tín hiệu của axit béo tự do còn bên phải là tín hiệu của triglyceritd trong mõ cá. Trên Hình 1b, Pic nội chuẩn xuất hiện với thời gian lưu ở 16,781 phút và có diện tích là 181133. Các etyl este ra trước pic nội chuẩn (phía trái) có tổng diện tích là 4.096.428. Các thành phần chưa chuyển hóa mono-, di-, triglycerid, ra sau (phía phải) chất nội chuẩn có tín hiệu rất nhỏ, không tính toán được.

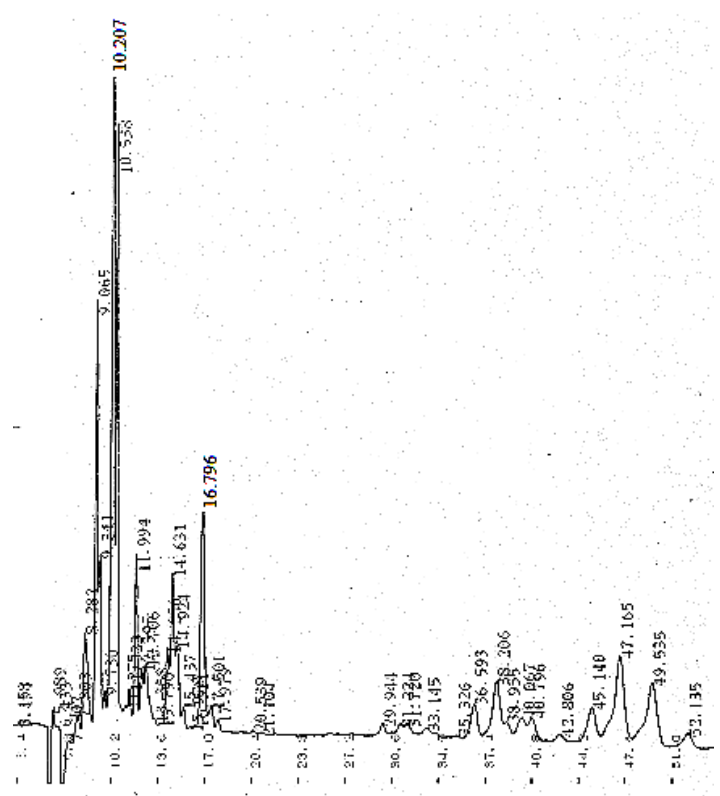

(a)

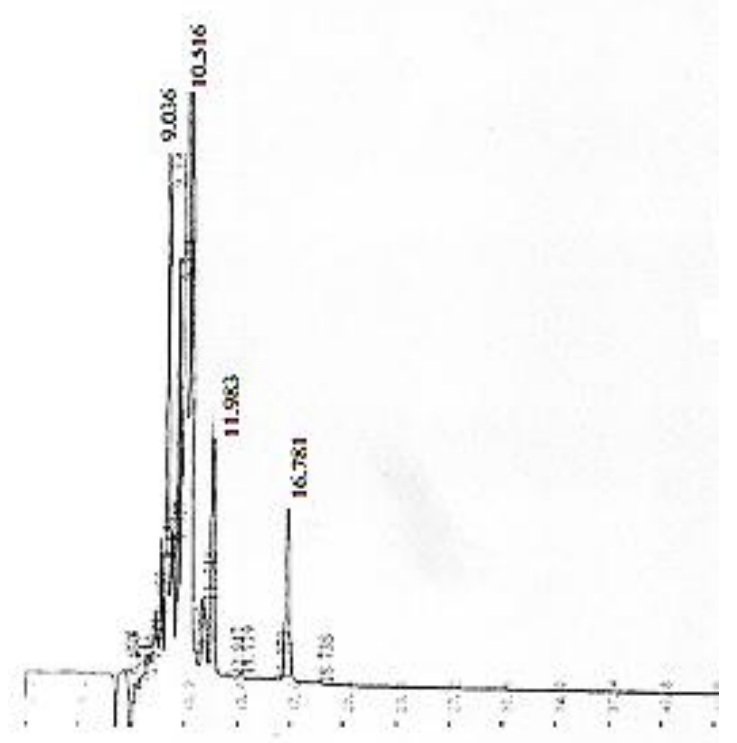

(b)

Hình 1. Sắc ký đồ UFLC của mỡ cá nguyên liệu (a) và etyl biodiesel sau phản ứng (b). 
Kết quả phân tích bằng UFLC cho thấy mức độ chuyển đổi este là rất cao (99\%); hàm lượng mono, di-, triglyxerit chỉ là dạng vết.

Bằng phương pháp Karl -Fisher mô tả ở mục 2.3a (phần thực nghiệm) đã xác định được hàm lượng nước trong FAEE là 560 ppm. Trong điều kiện độ ẩm cao, thì hàm lượng nước như vậy là đáp ứng được yêu cầu làm nhiên liệu. Bằng phương pháp chuẩn độ, như mô tả trong mục $2.3 \mathrm{~b}$ (phần thực nghiệm) đã xác định được hàm lượng FFA trong FAEE $<0,05 \%$.

Kết quả nghiên cứu cho thấy, phản ứng chuyển đổi este mỡ cá bằng etanol với xúc tác $\mathrm{KOH}$ rất nhạy cảm với vết nước. Khi sử dụng rượu etanol công nghiệp (96\%), hầu như không thu được sản phẩm. Thay rượu $96 \%$ bằng rượu $98 \%$ cũng không tách được etyl biodiesel do hồn hợp tạo huyền phù bền. Khi dùng rượu etanol tuyệt đối $(99.5 \%)$, việc tách sản phẩm trở nên bình thường.

Cũng cần nhận thấy rằng, phương pháp chế tạo etyl biodiesel sử dụng FAEE làm đồng dung môi có độ chuyển hóa este rất cao $(99 \%)$, nhưng hiệu suất lại cho đạt $>80 \%$. Lý do là vì độ nhớt của etyl biodiesel cao, bị dính bình lọ và chất làm khô trong quá trình xử lý.

\subsection{Xác định điểm sưong và điểm đông đặc của FAEE}

Điểm sương (Cloud Point $-\mathrm{CP}$ ) và điểm đông đặc (Pour Point -PP) là hai chỉ số liên quan đến độ nhớt, và do đó là độ lưu biến của etyl biodiesel khi thời tiết lạnh. Hai chỉ số này quan trong đối với khả năng đáp ứng tiêu chuẩn EN 14214 của nhiên liệu. Xác định điểm $\mathrm{CP}$ và $\mathrm{PP}$ để nếu chúng quá cao thì phải tím cách tách bớt phân đoạn giàu este của các axit béo no (palmitic, stearic..) trước khi sử dụng.

Điểm sương $(\mathrm{CP})$ là nhiệt độ mà ở đó bắt đầu xuất hiện kết tủa các tinh thể biodiesel. Điểm đông đặc (PP) là nhiệt độ mà ở đó biodiesel kết tinh hoàn toàn thành dạng rắn. Điểm sương và điểm đông đặc là một trong những tiêu chí để đánh giá chất lượng của biodiesel. Những loại biodiesel có điểm sương và điểm đông đặc thấp thì sẽ có chất lượng cao, phù hợp để sử dụng làm nhiên liệu cho động cơ, nhất là ở những nước có khí hậu lạnh. Ngược lại, những loại biodiesel có điểm sương và điểm đông đặc cao, sẽ dễ dàng bị kết tinh ở nhiệt độ thường, gây khó khăn cho việc phun nhiên liệu vào động cơ và làm tắc ống dẫn nhiên liệu. Những loại biodiesel như thế sẽ không phù hợp làm nhiên liệu, hoặc phải pha trộn với các loại biodiesel có $\mathrm{CP}$ và $\mathrm{PP}$ thấp hơn, hoặc phải tách bớt este của các axit béo no (axit palmitic, stearic...) để giảm độ nhớt, nhờ đó hạ thấp điểm sương và điểm đông đặc.

Điểm sương và điểm đông đặc của biodiesel được xác định theo phương pháp được mô tả ở mục 2.5 (phần thực nghiệm). Kết quả cho thấy, điểm sương của $\mathrm{FAEE}$ là $24^{\circ} \mathrm{C}$ và điểm đông đặc là $14^{\circ} \mathrm{C}$.

\subsection{Xác định hàm lương este của các axit béo không no chủ yếu trong dầu cá}

Mục tiêu của việc xác định hàm lượng các axit béo không no trong mỡ cá là để đánh giá tính khả thi của việc tách các este của các axit béo này làm thực phẩm chức năng, tạo giá trị gia tăng cao cho mỡ cá. Việc xác định hàm lượng của các axit béo không no trong mỡ cá tra dựa vào đường chuẩn của các chất este chuẩn tương ứng. Quy trình xác định được mô tả chi tiết trong phần thực nghiệm mục 2.6. Kết quả xác định được mô tả trên Bảng 3.

Bảng 3. Hàm lượng các este của các axit béo không no chủ yếu trong mỡ cá

\begin{tabular}{|c|c|c|c|}
\hline STT & СТPT & $\begin{array}{l}\text { Tên este cần xác } \\
\text { định hàm lượng }\end{array}$ & $\begin{array}{c}\text { Hàm } \\
\text { lượng } \\
\%\end{array}$ \\
\hline \multicolumn{4}{|c|}{ Omega-3 } \\
\hline 1 & $\mathrm{C} 18: 3 \mathrm{n} 3$ & Etyl linolenate & 1,57 \\
\hline 2 & C20:5n3 & $\begin{array}{l}\text { Etyl cis-5,8,11,14,17 } \\
\text {-Eicosapentaenoate }\end{array}$ & 1,00 \\
\hline 3 & $\mathrm{C} 22: 6 n 3$ & $\begin{array}{l}\text { Etyl cis- } 4,7,10,13,16 \text {, } \\
\text { 19-Docosahexaenoate }\end{array}$ & 0,65 \\
\hline \multicolumn{4}{|c|}{ Omega-6 } \\
\hline 4 & $\mathrm{C} 18: 2 \mathrm{n} 6 \mathrm{c}$ & Etyl Linoleate & 17.48 \\
\hline \multicolumn{4}{|c|}{ Omega-9 } \\
\hline 25 & $\mathrm{C} 18: \ln 9 \mathrm{c}$ & Etyl Cis-9-oleate & 36,06 \\
\hline
\end{tabular}


Kết quả trên Bảng 3 cho thấy, hàm lượng các axit Omega-3 trong dầu cá là quá ít; tỷ lệ khối lượng giữa Omega-3/Omega-6,-9 quá bé, không đáp ứng tỷ lệ quy định để làm thực phẩm chức năng. Tuy nhiên, trong mỡ cá axit béo no chủ yếu là axit stearic ( $36 \%)$, có nhiệt độ nóng chảy cao, có thể tách loại để thu phần mỡ còn lại làm làm dầu ăn.

\section{Kết luận}

1) Đã chế tạo được etyl biodiesel từ mõ cá tra bằng phương pháp mới sử dụng $\mathrm{FAEE}$ làm đồng dung môi. Nhờ khả năng hòa tan cả mỡ cá và etanol của $\mathrm{FAEE}$, phản ứng chuyển đổi este xảy ra trong môi trường đồng thể, thời gian phản ứng ngắn, độ chuyển hóa cao (99\%), ít chất thải; Các chỉ tiều chất lượng chủ yếu của etyl biodiesel đáp ứng tiêu chuẩn nhiên liệu ASTM D6751.

2) Đã xác định điểm sương $(\mathrm{CP})$ và điểm đông đặc $(\mathrm{PP})$ của etyl biodiesel, tương ứng là $24^{\circ} \mathrm{C}$ và $14^{\circ} \mathrm{C}$. Để sử dụng làm nhiên liệu động cơ trong thời tiết lạnh, có thể tách loại bớt este của các axit béo no, như axit palmitic, stearic... ( 39\%) bằng phương pháp kết tinh phân đoạn.

3) Đã xác định hàm lượng etyl este của các axit béo không no. Kết quả cho thấy hàm lượng este của axit oleic rất cao $(\sim 36 \%)$, còn hàm lượng este của các axit Omega-3,-6,-9 rất ít, không đảm bảo tỷ lệ giữa Omega-3/Omega-6,-9 để làm thực phẩm chức năng.

\section{Lời cảm ơn}

Công trình này là sản phẩm của đề tài 10/2017/HĐ-KHCN-TNB.ĐT/14-19/C22, thuộc Chương trình $\mathrm{KH} \& \mathrm{CN}$ phục vụ phát triển bền vững vùng Tây Nam Bộ, được tài trợ bởi Đại học Quốc gia Thành phố Hồ Chí Minh. Tập thể tác giả chân thành cảm ơn.

\section{Tài liệu tham khảo}

[1] N.H. Thanh, NT.T. Nguyen, N.T.P. Thoa, Sonochemicals synthesis of biodiesel from catfist oil, Journal of Science and Technology Development 12 (3)(2009) 51-61 (in Vietnamese).

[2] R. Yahyaee, B. Ghobadian, G. Najafi, Waste fish oil biodiesel as a source of renewable fuel in Iran, Renewable and Sustainable Energy, Reviews 17 (2013) 312-319. https://doi.org/- 10.1016/j.rser. 2012.09.025.

[3] Y. Mulugetta, Evaluating the economics of biodiesel in Africa, Renewable and Sustainable Energy Reviews 13 (2009) 1592-1598. https:// doi.org/10.1016/j.rser.2008.09.011.

[4] S. Sathivel, W. Prinyawiwatkul, J.M. King, C.C. Grimm, and S. Steven Lloyd, Oil Production from Catfish Viscera, AOCS 80 (4) (2003) 337-338. https://doi.org/-10.1007/s- 11746-003-0707-z.

[5] V.T.V. Dung, N.X. Trung, L.D. Phuong, L.V. Boi, Analysis of FFA in catfish oil used in biodiesel production, Journal of Chemistry 48 (4C) (2010) 522-528 (in Vietnamese).

[6] B. Abderrahim, M. Mercedes, A. Jose, A comparative study of the production of ethyl esters from vegetable oils as a biodiesel fuel optimization by factorial design, Chemical Engineering Journal 134 (2007) 93-99. https:// doi.org/10.1016/j.cej.2007.03.077.

[7] F. Sundus, M.A. Fazel, H.H. Masjuki, Tribology with biodiesel: a study on enhancing biodiesel stability and its fuel properties, Renew and Sustain. Energy Rev. 70 (2017) 399-412. https:// doi.org/10.1016/j.rser.2016.11.217.

[8] W. Chen, Y. Wang, M. Ding, S. Shi, Z. Yang, Crystallization behaviors and rheological properties of biodiesel derived from methanol and ethanol, Fuel 207 (2017) 503-50. https://doi.org/ 10.1016/j.fuel.2017.06.121.

[9] P. Verma, M.P. Sharma, G. Dwivedi, Impact of alcohol on biodiesel production and properties, Renew and Sustain. Energy Rev. 56 (2016) 319333. https://doi.org/10.1016/j.rser.2015.11.048.

[10] M. Cernoch, F. Skopal, M. Hajek, Separation of reaction mixture after ethanolysis of rapeseed oil, Eur. J. Lipid Sci. Technol. 111 (2009) 663-668. https://doi.org/-10.1002/ejlt.- 200800255.

[11] S.S. Ragit, S.K. Mohapatra, K. Kundu, R. Karmakan, Methanolysis and ethanolysis of raw hemp oil: biodiesel production and fuel characterization, Int. J. Eng. Res. Technol. 2 (2013) 1-10. Corpus ID: 137693125.

[12] A. Bouaid, M. Martinez, J.A. Aracil, Comparative study of the production of ethyl esters from vegetable oils as a biodiesel fuel optimization by 
factorial design, Chem. Eng. J. 134 (2007) 93-99. https://doi.org/10.1016/j.cej.2007.03.077.

[13] R. Nikhom, C. Tongurai, Production development of ethyl ester biodiesel from palm oil using a continuous deglycerolisation process, Fuel 117 (2014) 926-931. https://doi.org/10.1016/j.fuel. 2013.10.018.

[14] G.M. Hincapie, S. Valange, J. Barrault, J.A. Moreno, D.P. Lopez, Effect of microwaveassisted system on transesterification of castor oil with ethanol, Univ. Sci. 19 (2014) 193-200. http:// dx.doi.org/10.11144/Javeriana.SC19-3.emas
[15] R.R. Nasaruddin, M.Z. Alam, M.S. Jami, A. Salihu, Statistical optimization of ethanol-based biodiesel production from sludge palm oil using locally produced candida cylindracea lipase, Waste Biomass Valor. 7 (2016) 87-95. https://doi. org/10.1007/s-12649-015-9424-x.

[16] M. Cernoch, M. Hajek, F. Skopal, Study of effects of some reaction conditions on ethanolysis of rapeseed oil with dispergation, Bioresour. Technol. 101 (2010) 1213-1219. https://doi.org/ 10.1016/j.biortech.2009.09.033. 